\title{
Oral high dose ascorbic acid treatment for one year in young CMTI A patients: a randomised, double-blind, placebo-controlled phase II trial
}

\author{
Camiel Verhamme*1, Rob J de Haan², Marinus Vermeulen1, Frank Baas ${ }^{1}$, \\ Marianne de Visser $^{1}$ and Ivo $\mathrm{N}$ van Schaik ${ }^{1}$
}

\begin{abstract}
Address: ${ }^{1}$ Department of Neurology and Clinical Neurophysiology, Academic Medical Centre, University of Amsterdam, PO Box 22660, 1100 DD Amsterdam, The Netherlands and ${ }^{2}$ Department of Clinical Epidemiology and Biostatistics, Academic Medical Centre, University of Amsterdam, PO Box 22660, 1100 DD, Amsterdam, The Netherlands

Email: Camiel Verhamme* - c.verhamme@amc.uva.nl; Rob J de Haan - r.j.dehaan@amc.uva.nl; Marinus Vermeulen - m.vermeulen@amc.uva.nl; Frank Baas - f.baas@amc.uva.nl; Marianne de Visser - m.devisser@amc.uva.nl; Ivo N van Schaik - i.n.vanschaik@amc.uva.nl

* Corresponding author
\end{abstract}

Published: 12 November 2009

BMC Medicine 2009, 7:70 doi:10.1 |86/174|-70/5-7-70
Received: 30 October 2009

Accepted: 12 November 2009

This article is available from: http://www.biomedcentral.com/I74 I-70 I5/7/70

(C) 2009 Verhamme et al; licensee BioMed Central Ltd.

This is an Open Access article distributed under the terms of the Creative Commons Attribution License (http://creativecommons.org/licenses/by/2.0), which permits unrestricted use, distribution, and reproduction in any medium, provided the original work is properly cited.

\begin{abstract}
Background: High dose oral ascorbic acid substantially improved myelination and locomotor function in a Charcot-Marie-Tooth type IA mouse model. A phase II study was warranted to investigate whether high dose ascorbic acid also has such a substantial effect on myelination in Charcot-Marie-Tooth type IA patients and whether this treatment is safe.
\end{abstract}

Methods: Patients below age 25 years were randomly assigned to receive placebo or ascorbic acid (one gram twice daily) in a double-blind fashion during one year. The primary outcome measure was the change over time in motor nerve conduction velocity of the median nerve. Secondary outcome measures included changes in minimal $\mathrm{F}$ response latencies, compound muscle action potential amplitude, muscle strength, sensory function, Charcot-Marie-Tooth neuropathy score, and disability.

Results: There were no significant differences between the six placebo-treated (median age 16 years, range 13 to 24$)$ and the five ascorbic acid-treated (19, 14 to 24) patients in change in motor nerve conduction velocity of the median nerve (mean difference ascorbic acid as opposed to placebo treatment of $1.3 \mathrm{~m} / \mathrm{s}$, confidence interval -0.3 to $3.0 \mathrm{~m} / \mathrm{s}, P=0.1 \mathrm{I}$ ) or in change of any of the secondary outcome measures over time. One patient in the ascorbic acid group developed a skin rash, which led to discontinuation of the study medication.

Conclusion: Oral high dose ascorbic acid for one year did not improve myelination of the median nerve in young Charcot-Marie-Tooth type IA patients. Treatment was relatively safe.

Trial registration: Current Controlled Trials ISRCTN56968278, ClinicalTrials.gov NCT0027I635. 


\section{Background}

Charcot-Marie-Tooth type 1A (CMT1A), also known as Hereditary Motor and Sensory Neuropathy type Ia (HMSN Ia), is the most prevalent hereditary peripheral neuropathy (approximately 1:5,000 people) [1]. CMT1A is an autosomal dominant disease, most often caused by a $1.5 \mathrm{Mb}$ duplication on chromosome 17 , giving rise to three copies of the peripheral myelin protein 22 (PMP22)gene. Histologically, there are signs of dysmyelination, of active de- and remyelination especially during the first years of life, and of axonal loss [2,3]. The conduction velocities of the peripheral nerves are slow very early in life and after the age of approximately five years longitudinal data show that the conduction velocities remain fairly stable, consistent with a fairly constant myelination status [4-7]. Compound muscle action potential (CMAP) amplitudes as recorded from distal leg muscles are found to decrease during the first two decades of life, indicating increasing secondary axonal dysfunction [8]. This increasing axonal dysfunction is responsible for the development of symptoms and signs of predominantly distal muscle weakness, atrophy, and sensory abnormalities, in the legs more than the arms $[8,9]$. One of the factors determining the severity of secondary axonal dysfunction is the degree of initial abnormal myelination [9]. Until now, therapy is symptomatic and aims at maintaining functional abilities and learning compensation mechanisms. Therapy directed at restoration of myelination is expected to be most beneficial in young patients, as more secondary axonal dysfunction may be prevented than in older patients [7].

An in vitro study showed that high doses of ascorbic acid may repress PMP22 gene expression by acting on intracellular cyclic adenosine monophosphate levels and adenylate cyclase activity [10]. This may explain why in a mouse model for CMT1A, in which the animals overexpress human $P M P 22$, ascorbic acid induced remyelination and improved locomotor functioning [11]. Mice aged two to four months treated with orally administered high doses of ascorbic acid once a week during three months showed increased percentages of myelinated fibres (from 25 to $70 \%$ ) and increased myelin sheath thickness in the sciatic nerves with fairly normal $g$ ratios [11]. Electrophysiological data have not been published in this study, but the substantial improvements of myelination parameters in the histological analysis suggested that the same may hold true for nerve conduction. Nerve conduction velocities are a non-invasive surrogate marker for myelination which are relatively easily obtainable in longitudinal studies in CMT1A patients [4-7]. For this reason, we initiated a proof of principle study to investigate whether ascorbic acid also has a substantial effect on myelination in CMT1A patients. This may in turn also have a positive effect on axonal function and in that respect on clinical impairments and disability. Therefore, we performed a single-centre, randomised, double-blinded, phase II study comparing a high dose ascorbic acid with a placebo during one year to assess the effects of ascorbic acid on myelination and its safety in young CMT1A patients.

\section{Methods}

CMT1A patients were recruited from the outpatient department of neurology at the Academic Medical Centre (AMC), University of Amsterdam and via the Dutch Neuromuscular Patient Association (Vereniging Spierziekten Nederland). They were assessed for eligibility between December 2005 and June 2006. Inclusion criteria were: DNA-proven diagnosis of CMT1A; age range 12 to 25 years; clinically affected status defined as muscle weakness of at least the foot dorsiflexors. Exclusion criteria were: other known disease or medication that may cause a neuropathy, chronic alcohol abuse, regular use of ascorbic acid before the study, clinical or ultrasound signs of nephrolithiasis, reduced glomerular filtration rate, iron overload, no regular dental control at the dentist, pregnancy or active pregnancy wish for women, psychiatric co-morbidity which may influence compliance, reluctance to undergo nerve conduction studies, a low CMAP amplitude of the abductor pollicis brevis muscle (negative peak $<0.5 \mathrm{mV}$ ) hindering proper determination of the motor nerve conduction velocity ( $\mathrm{MNCV}$ ) of the median nerve.

The local medical ethics committee approved the study protocol. All patients, and where appropriate the parents, gave written informed consent to participate in the study. This study has been registered in ClinicalTrials.gov, number NCT00271635, and in Current Controlled Trials, number ISRCTN56968278.

\section{Procedure}

Eligible patients were randomly allocated to oral ascorbic acid or placebo. The pharmacist, who did not have any further role in the study, generated a computerized randomization sequence. Participants and investigators were unaware of the treatment assignment. The tolerable upper intake level of ascorbic acid for adults is $2 \mathrm{~g} /$ day, for children 14 to 18 years $1.8 \mathrm{~g} / \mathrm{day}$, and for children 9 to 13 years $1.2 \mathrm{~g} /$ day. A higher intake is acceptable with clinical monitoring [12]. Treatment was administered in a double-blind fashion for 12 months and was either four capsules containing $250 \mathrm{mg}$ ascorbic acid twice daily (daily dose: 2 g), or four capsules containing placebo with identical size, colour, shape, and taste twice daily. Patients were assessed for all outcome measures at baseline and at 6 and 12 months follow-up by the same investigator (C.V.). Given the explorative nature of the phase II study, we used a primary outcome measure at the impairment level to test the efficacy of ascorbic acid; the mean change 
over time of the MNCV of the median nerve at 12 months follow-up, which we consider the best non-invasive surrogate marker for changes in myelination $[9,13,14]$. At the non-dominant side of the body large surface recording electrodes $(2.0 \times 2.6 \mathrm{~cm})$ were attached over the surface of the abductor pollicis brevis muscle at standardised sites defined by anatomical landmarks. Temperature was maintained between 32 and $34^{\circ} \mathrm{C}$ as measured at distal recording sites. The median nerve was stimulated at the wrist and elbow, and the MNCV was calculated. The secondary outcomes included changes over time at 12 months of other measures at the impairment and disability level. The mean change over time of the minimal $\mathrm{F}$ response latency of the median nerve was an additional non-invasive surrogate marker for changes in myelination. The mean change over time of the CMAP amplitude (negative peak) recorded from the abductor pollicis brevis muscle was a non-invasive surrogate marker for changes in axonal function $[9,14]$. The mean change over time of strength of the three point grip and the foot dorsiflexors as assessed with hand-held dynamometry were indicators for changes in arm and leg strength, respectively $[15,16]$. The median change over time of the Inflammatory neuropathy cause and treatment sensory sum score (ISS) assessed changes in sensory function [17]. It comprises vibration and pinprick sense plus a two-point discrimination value and ranges from 0 (normal sensation) to 20 (maximum sensory deficit). The median change over time of the Charcot-Marie-Tooth neuropathy score (CMTNS) assessed changes in an overall composite impairment score [18]. It comprises items from history, clinical and electrophysiological investigations and ranges from 0 (no deficit) to 36 (maximal deficit). The mean change over time in the AMC linear Disability Score (ALDS) was an indicator for changes in disability [19]. It ranges from 0 (dead) to 100 (fully able). The median change over time of the overall disability sum score (ODSS) was another indicator for changes in disability [20]. It comprises arm and leg items and ranges from 0 (no disability) to 12 (maximum disability). Indicators for changes in functional performance were the mean change over time of the time needed for the nine hole peg test $[16,21]$, and of the time needed for the $50 \mathrm{~m}$ walking test, which we decided would be more sensitive to change than the $10 \mathrm{~m}$ walking test [16]. Motor unit number estimation of the thenar muscles was determined in the context of another study [22], and will be reported separately.

Adverse events and laboratory values were monitored every three months or more often if necessary, and were reviewed by an independent Data Safety Monitoring Board. A repeat ultrasound of the kidneys was done at 12 months. Capsule counts were performed every three months to monitor treatment adherence. At the end of the study the success of blinding was evaluated by asking the participant and the investigator separately which trial medication they thought the participant had used (placebo, ascorbic acid or 'I really don't know').

\section{Statistical analysis}

We deduced from the substantial improvement in histological myelination parameters of the animal experimental study that at least a mean improvement of the MNCV of the median nerve of $10 \mathrm{~m} / \mathrm{s}$ should be detectable in the ascorbic acid-treated group as opposed to the placebotreated group. Such an improvement was considered potentially clinically meaningful. In a previous study on 46 CMT1A patients, the mean MNCV of the median nerve was found to be $23 \mathrm{~m} / \mathrm{s}$ with a standard deviation (SD) of 5.3 [9]. As there were no SDs for possible changes in MNCV, we conservatively used SDs of 5.3 to calculate group sizes. Six patients per group were required to detect a difference of $10 \mathrm{~m} / \mathrm{s}$ with $80 \%$ power and a two-sided alpha level of 0.05 using the unpaired $t$ test. Randomised patients with at least one follow-up measure of the primary outcome were analyzed according to the intentionto-treat principle. In case of incomplete data, we used the last observation carried forward approach. The mean or median change scores from baseline to final follow-up of the patients receiving ascorbic acid and those receiving placebo were presented together with the differences in these change scores between the treatment groups using unpaired $t$ test or Mann-Whitney $U$ test, when appropriate. Statistical uncertainty was quantified via corresponding $95 \%$ confidence intervals for the differences in change scores between the treatment groups. Additionally, we analysed the MNCV of the median nerve at follow-up, given the MNCV of the median nerve at baseline, using analysis of covariance to evaluate the effect of being treated either with ascorbic acid or placebo [23]. For the analysis of covariance we presented the averaged difference together with the 95\% confidence interval. All analyses were done with SPSS 15.0 for Windows (SPSS Inc. Chicago, Illinois, USA).

\section{Results}

Sixteen of the 29 patients initially screened for the study did not meet the inclusion criteria (Figure 1). Eight patients refused to participate for various reasons. Four patients, who responded via the patients' association, had another form of CMT. Four patients already used supplemental ascorbic acid. From the randomised 13 patients one female participant in the placebo group aged 18 years with a baseline MNCV of the median nerve of $21 \mathrm{~m} / \mathrm{s}$ was excluded during the study because of a pregnancy wish before the six months' assessment. One male participant in the ascorbic acid group aged 21 years with a baseline MNCV of the median nerve of $16 \mathrm{~m} / \mathrm{s}$ developed a skin rash after the first days of study medication use which disappeared after stopping the study medication. 


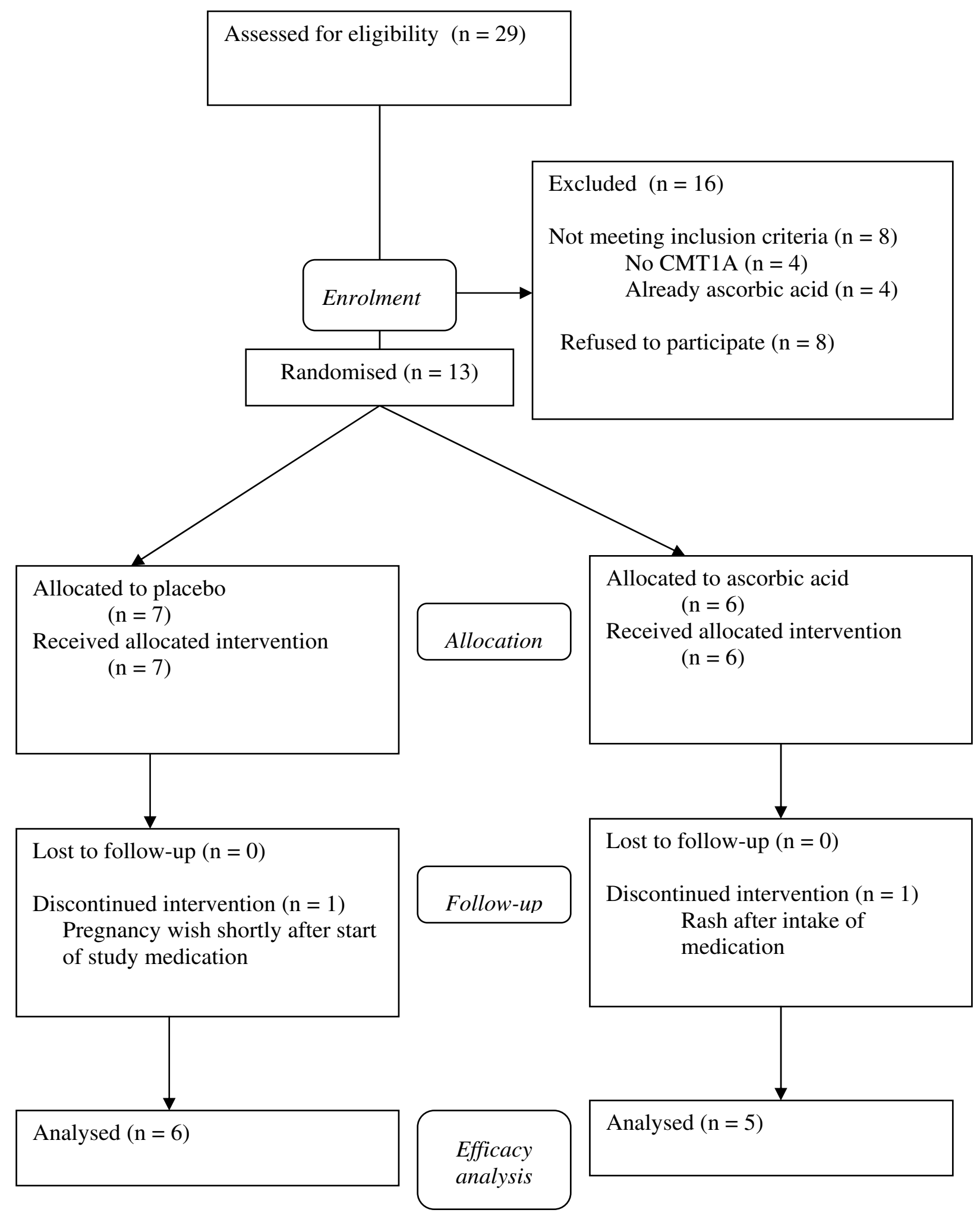

Figure I

Flow diagram of the trial. 
Baseline characteristics of the 11 patients in which at least one primary outcome measure during follow-up was obtained are described in Table 1. Both groups were fairly similar with regard to baseline characteristics. In each group, one participant had a follow-up until six months: in the placebo group one participant discontinued medication due to gastrointestinal complaints and in the ascorbic acid group one participant failed to attend the outpatient clinic afterwards. All the other participants had a follow-up until 12 months.

The MNCVs of the median nerve over time of individual participants in the placebo and ascorbic acid treated groups are shown in figure $2 \mathrm{~A}$ and $2 \mathrm{~B}$, respectively. Table 2 summarizes the primary and secondary outcome measures. The mean change in MNCV of the median nerve over time was not different between the treatment groups $(P=$ 0.11 ). Additionally, analysis of covariance showed a nonsignificant averaged difference of $1.3 \mathrm{~m} / \mathrm{s}$ (confidence interval -0.4 to $2.9, P=0.12$ ) in favour of the ascorbic acid as opposed to the placebo treated group, given the MNCVs of the median nerve at baseline. None of the secondary outcome measures showed significant score changes.

Adverse events were registered for all randomised participants $(n=13)$ who were allocated trial medication. In the placebo group three out of the seven included participants had gastrointestinal complaints during the study, while in the ascorbic acid group one of the six participants had an adverse event. In the placebo group one female participant had severe complaints of cramps and diarrhoea to such an extent that she discontinued the study medication after just six months, one participant had feelings of nausea during the nine months and 12 months visits, and one participant had feelings of nausea and cramps at three months. The latter individual was excluded from the study because of a pregnancy wish just after three months (Figure 1). In the ascorbic acid group one adult participant developed a skin rash after the first days of treatment (see also Figure 1). This was interpreted as an allergic reaction; the rash disappeared after stopping the study medication. None of the 13 participants complained about renal colic or reported tooth problems. There were no relevant changes in laboratory values. None of the nine participants who attended at 12 months had signs of kidney stones or renal disorders on a repeat ultrasound of the kidneys. Of the participants who left the study before 12 months no repeat ultrasound was made.

Counts of returned capsules showed that the six placebo treated participants and the five ascorbic acid treated participants both used $88 \%$ of the capsules on average during the study period. In the ascorbic acid group three out of five participants did not know what treatment they were using, one correctly and one incorrectly identified group assignment. In the placebo group four out of six participants did not know their treatment allocation and two correctly identified group assignment. The investigator did not know treatment allocation of any participant. Forced guessing corresponded with correct group allocation in three out of five in the ascorbic acid group and four out of six in the placebo group. None of the participants reported the intake of supplemental ascorbic acid during the study period.

\section{Discussion}

In this phase II study high dose ascorbic acid given during one year to young CMT1A patients did not lead to a positive predefined effect on myelination, assessed as a differ-

Table I: Baseline characteristics of study participants described for primary and secondary outcome measures.

\begin{tabular}{|c|c|c|}
\hline & $\begin{array}{c}\text { Placebo } \\
(n=6)\end{array}$ & $\begin{array}{c}\text { Ascorbic acid } \\
(n=5)\end{array}$ \\
\hline Male/Female (numbers) & $2 / 4$ & $3 / 2$ \\
\hline Age $(\text { years })^{b}$ & $16(13-24)$ & $19(14-24)$ \\
\hline Median nerve $\mathrm{MNCV}(\mathrm{m} / \mathrm{s})^{\mathrm{a}}$ & $17.9(6.0)$ & $17.2(1.7)$ \\
\hline Median nerve minimal $\mathrm{F}$ response latency $(\mathrm{ms})^{\mathrm{a}}$ & $83.8(28.0)^{*}$ & $77.1(10.6)$ \\
\hline CMAP amplitude abductor pollicis brevis muscle $(\mathrm{mV})^{\mathrm{a}}$ & $3.9(1.1)$ & $4.0(1.2)$ \\
\hline Three point grip $(\mathrm{N})^{\mathrm{a}}$ & $50.9(14.4)$ & $73.8(24.7)$ \\
\hline Foot dorsiflexors $(\mathrm{N})^{\mathrm{a}}$ & $79.5(14.0)$ & $91.1(26.9)$ \\
\hline ISSb & $2(0-8)$ & $3(I-6)$ \\
\hline CMTNSb & $10(7-20)$ & $13(7-17)$ \\
\hline ODSSb & $3(2-4)$ & $2(2-4)$ \\
\hline ALDSa & $86.8(6.5)$ & $89.0(0.5)$ \\
\hline Nine hole peg test $(s)^{\mathrm{a}}$ & $26.3(6.6)$ & $23.5(1.8)$ \\
\hline $50 \mathrm{~m}$ walking $(\mathrm{s})^{\mathrm{a}}$ & $31.9(2.0)$ & $29.2(3.2)$ \\
\hline
\end{tabular}

a Mean (standard deviation) bMedian (range) $* \mathrm{n}=5$

Abbreviations: ALDS = Academic Medical Centre linear disability score; CMAP = Compound muscle action potential; CMTNS = Charcot-MarieTooth neuropathy score; ISS = inflammatory neuropathy cause and treatment sensory sum score; MNCV = motor nerve conduction velocity;

ODSS $=$ overall disability sum score 
Table 2: Primary and secondary treatment outcomes according to assigned treatment.

\begin{tabular}{|c|c|c|c|c|}
\hline & $\begin{array}{l}\text { Placebo } \\
(n=6)\end{array}$ & $\begin{array}{l}\text { Ascorbic acid } \\
(n=5)\end{array}$ & & \\
\hline & Change & Change & Difference & $P$ value \\
\hline Median nerve $\mathrm{MNCV}(\mathrm{m} / \mathrm{s})^{\mathrm{a}}$ & $-0.8(0.9)$ & $0.5(1.5)$ & I.3 $(-0.3-3.0)$ & 0.11 \\
\hline Median nerve minimal F response latency $(\mathrm{ms})^{\mathrm{a}}$ & $3.5(8.0)^{*}$ & $-5.6(4.4)$ & $-9.1(-18.5-0.3)$ & 0.06 \\
\hline CMAP amplitude abductor pollicis brevis muscle $(\mathrm{mV})^{\mathrm{a}}$ & $-0.02(0.9)$ & $-0.2(0.8)$ & $-0.1(-1.3-1.1)$ & 0.79 \\
\hline Three point grip $(\mathrm{N})^{\mathrm{a}}$ & $-3.0(9.2)$ & $3.4(9.0)$ & $6.4(-6.1-18.9)$ & 0.28 \\
\hline Foot dorsiflexors $(\mathrm{N})^{\mathrm{a}}$ & $-5.1(17.6)$ & $0.6(15.6)$ & $5.6(-17.3-28.6)$ & 0.59 \\
\hline ISSb & $0(-4-1)$ & $-2(-2-1)$ & $-2(-2-2)$ & 0.30 \\
\hline CMTNSb & $(-5-4)$ & $-2(-3-1)$ & $-3(-6-3)$ & 0.14 \\
\hline ODSSb & $0(0-1)$ & $0(-2-0)$ & $0(-2-0)$ & 0.18 \\
\hline ALDSa & $1.0(3.7)$ & $0.3(0.4)$ & $-0.6(-4.5-3.2)$ & 0.30 \\
\hline Nine hole peg test $(s)^{a}$ & $-3.5(2.8)$ & $-2.0(1.8)$ & $1.5(-1.8-4.8)$ & 0.32 \\
\hline $50 \mathrm{~m}$ walking $(\mathrm{s})^{\mathrm{a}}$ & $-0.6(1.9)$ & $-0.9(1.8)$ & $-0.3(-2.9-2.2)$ & 0.77 \\
\hline
\end{tabular}

Change $={ }^{a}$ mean (standard deviation) or ${ }^{b}$ median (range) change scores from baseline to final follow-up. Difference $=$ difference in ${ }^{a}$ mean or $b$ median change scores $(95 \%$ confidence interval) of the patients receiving ascorbic acid and those receiving placebo. $P$-value $=P$-value for a the unpaired $t$ test (equal variances assumed) or bthe Mann-Whitney $U$ test. $* n=5$

Abbreviations: ALDS = Academic Medical Centre linear disability score; CMAP = compound muscle action potential; CMTNS = Charcot-Marie-

Tooth neuropathy score; ISS = inflammatory neuropathy cause and treatment sensory sum score; MNCV = motor nerve conduction velocity;

ODSS = overall disability sum score

ence of the MNCV of the median nerve of $10 \mathrm{~m} / \mathrm{s}$ between the ascorbic acid- and placebo-treated patients. We found a non-significant difference in mean $\mathrm{MNCV}$ change scores between ascorbic acid as opposed to placebo treatment of $1.3 \mathrm{~m} / \mathrm{s}$ with an upper limit of the confidence interval of $3 \mathrm{~m} / \mathrm{s}$. Neither could we demonstrate significant effects of ascorbic acid for any of the secondary outcome measures, including minimal $\mathrm{F}$ response latency of the median nerve, CMAP amplitude, muscle strength, sensory function and disability. The treatment consisting of $2 \mathrm{~g}$ per day during one year was relatively safe, although there was one serious adverse event: one patient in the ascorbic acid group developed a rash, which led to discontinuation of the study medication. A delayed type hypersensitivity to ascorbic acid has been seldom reported [24].

The rationale for our study was derived from the results of a study, showing a robust effect of high doses ascorbic acid on myelination in a PMP22 over-expressing mouse model [11]. To our knowledge these results have not been reproduced in the same or other animal models. A 12month randomised, double-blind, placebo controlled trial in 81 CMT1A children aged 2 to 16 years with comparable high-dose oral ascorbic acid $(30 \mathrm{mg} / \mathrm{kg} /$ day) did not show an improvement on motor nerve conduction velocity, CMAP amplitudes or functional abilities but treatment was safe and well tolerated [25]. A two-year non-randomised open-label pilot study compared a group of 12 adult patients starting with $5 \mathrm{~g}$ of ascorbic acid daily with a group of 10 age-matched untreated patients [26]. Five out of 12 treated patients (42\%) tolerated $5 \mathrm{~g}$ daily for the entire study period; two $(17 \%)$ were able to finish the study period after lowering the dose to $2.5 \mathrm{~g}$ daily; five (42\%) discontinued treatment, mainly due to gastrointestinal side effects. Nerve conduction velocities, CMAP amplitudes and the CMTNS did not improve over time when either the whole group of 12 patients initially receiving ascorbic acid, or the five patients who received 5 $\mathrm{g}$ daily during the entire study period, were compared with the control group [26]. This study showed that adverse events limit the tolerable doses in CMT1A patients and did not provide evidence for the effectiveness of doses as high as $5 \mathrm{~g}$ daily.

The discrepancy in effectiveness of ascorbic acid between the mouse model and humans may have several explanations. PMP22 gene over-expression may be higher in the mouse model, as this model has seven extra copies of the human PMP22 gene, while human patients only have one extra copy. Thus, myelination is more severely affected in the mouse model, as indicated by a considerably lower mean MNCV in the mouse model as compared to that in CMT1A patients $[9,27]$. Whether this difference in myelination of the peripheral nerves at outset evokes a different response to high dose ascorbic acid is unknown. The effectiveness of PMP22 gene repression in humans may be too small to notice a clear effect on myelination. Another explanation may be the fact that ascorbic acid metabolism in humans is distinct from that in mice. Humans derive ascorbic acid entirely from dietary sources, while mice are able to synthesize ascorbic acid [28]. There may also be a difference between mice and humans with regard to the uptake of ascorbic acid or its metabolic intermediates at the tissue and cellular level, leading to different effects. 

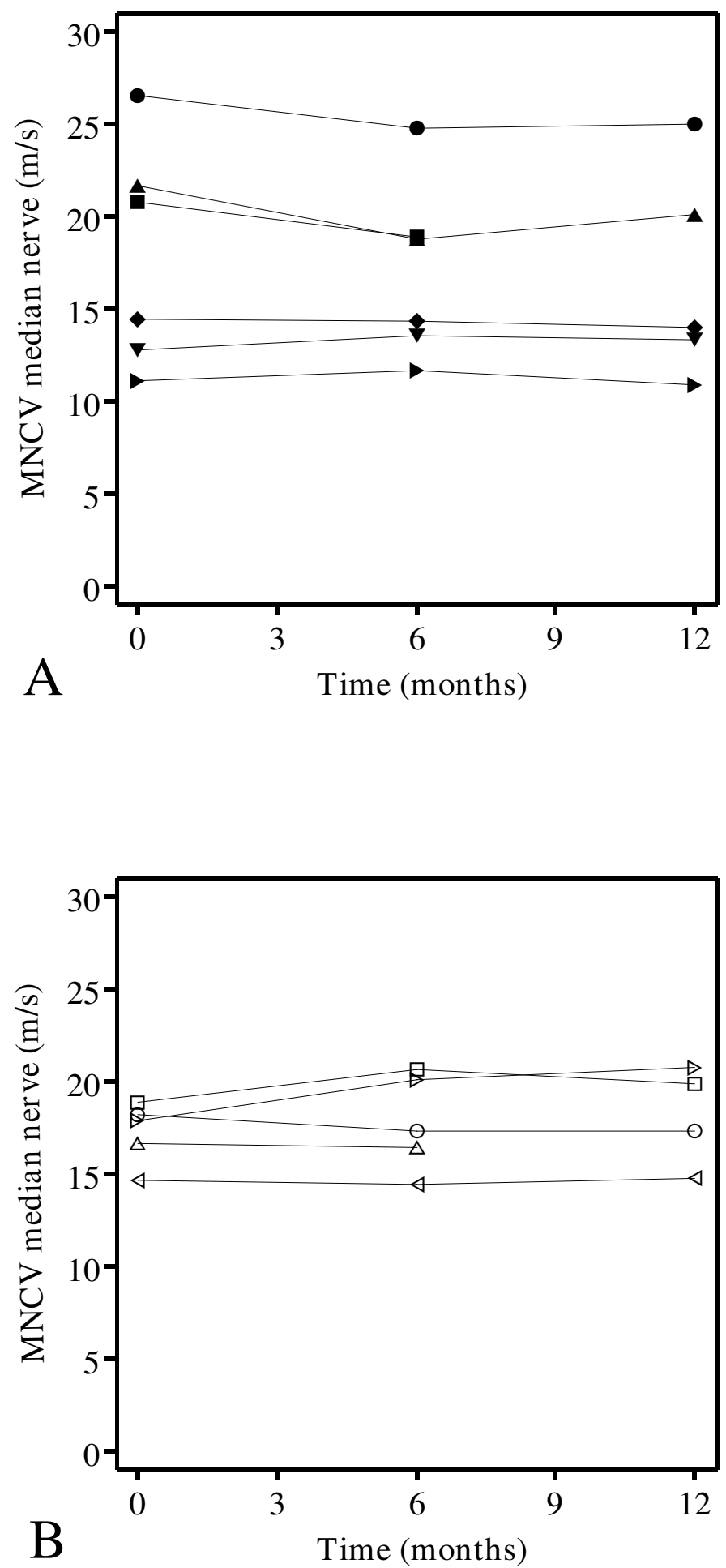

Figure 2

Motor nerve conduction velocities of the median nerve over time. Motor nerve conduction velocity (MNCV) of the median nerve $(\mathrm{m} / \mathrm{s})$ over time (months) in the placebo $(A)$ and ascorbic acid $(B)$ treated participants. Each connected symbol corresponds with an individual participant. 
Some strengths of this study should be addressed. To answer the question whether the substantial positive effects of high dose ascorbic acid on myelination in a CMT1A mouse model may be reproducible in humans a non-invasive surrogate marker for myelination (MNCV of the median nerve) was chosen as primary efficacy outcome measure because this measure reflects the intended biological effect (induction of remyelination) as close as possible. MNCVs are validated measures [14] and commonly used as a non-invasive surrogate marker for myelination in CMT1A studies [4-7]. We assumed that a followup of one year should be long enough to detect at least any indication of remyelination. Theoretically, this remyelination should secondarily lead to a decrease in axonal dysfunction. This introduces more uncertain factors like the capacity of remyelination to prevent axonal dysfunction and even to restore axonal function over time in CMT1A patients. This is why parameters like the composite CMTNS were included as secondary outcome measures. It is of note that the CMTNS does not include any measure of myelination, and thus was considered not to be suitable as the primary outcome measure in our study. Finally, we included young patients who may benefit most from treatment, as more axonal dysfunction may be prevented than in older patients.

Some limitations of this study should also be addressed. In retrospect, the conversion from the improvement of myelination parameters in the histological analysis in the mouse study [11] to the intended improvement in humans, $10 \mathrm{~m} / \mathrm{s}$ for the MNCV of the median nerve, may have been too optimistic. In CMT1A there are no data available about the minimal increase of MNCVs giving rise to a clinically meaningful secondary effect on axonal function and more importantly on disability. However, we hypothesized that a $10 \mathrm{~m} / \mathrm{s}$ increase was potentially clinically relevant and we performed a power calculation based on this, leading to small numbers of patients in each group. Since our goal was to find out whether high dose ascorbic acid had the same substantial effect on myelination as had been found in the animal study, we decided to carry out a small proof of principle study first. The non-significant difference in mean MNCV change scores between ascorbic acid and placebo treated patients we found is in accordance with the non-significant difference in a randomised controlled trial in a much larger group of patients [25] and is in our opinion too little to have enough potential clinical relevance to initiate studies with larger numbers of patients, although we are aware that these are under way [29]. Moreover, the difference we found may well be due to normal measurement variation inherent to conduction studies as suggested by the fact that the major part of this modest difference was due to a decrease in MNCV over time in the placebo group and not to an increase in MNCV over time in the ascorbic acid group.

\section{Conclusion}

This randomised double-blind, placebo-controlled, phase II trial with high dose ascorbic acid ( 2 g per day) for one year in children and young adults with CMT1A was initiated as a proof of principle study but did not show an improvement of myelination in the median nerve. In our hands treatment with $2 \mathrm{~g}$ per day during one year was relatively safe. Thus, evidence is accumulating that ascorbic acid does not have the same robust positive effect on myelination and functional abilities as was shown in the PMP22 over-expressing mouse model [11] in neither child nor (young) adult CMT1A patients $[25,26]$.

\section{Abbreviations}

ALDS: Academic Medical Centre linear disability score; AMC: Academic Medical Centre; CMAP: compound muscle action potential; CMT: Charcot-Marie-Tooth; CMTNS: Charcot-Marie-Tooth neuropathy score; CMT1A: CharcotMarie-Tooth type 1A; HMSN Ia: Hereditary Motor and Sensory Neuropathy type Ia; ISS: inflammatory neuropathy cause and treatment sensory sum score; MNCV: motor nerve conduction velocity; ODSS: overall disability sum score; PMP22: peripheral myelin protein 22; SD: standard deviation.

\section{Competing interests}

The authors declare that they have no competing interests.

\section{Authors' contributions}

$\mathrm{CV}$ participated in the design of the study, carried out the study, performed the statistical analysis and drafted the manuscript. RdH helped with the statistical analysis and helped to draft the manuscript. MV, FB and MdV participated in its design and helped to draft the manuscript. IvS participated in its design and coordination, helped with the statistical analysis and helped to draft the manuscript. All authors read and approved the final manuscript.

\section{Acknowledgements}

We thank the Dutch Neuromuscular Patient Association (Vereniging Spierziekten Nederland) for informing patients about the study, the patients for their participation and A. Vyth, pharmacist, and W. Veenstra, pharmacist assistant, for randomising and delivering the study medication. We acknowledge the members of the Data Safety Monitoring Board: R.T. Krediet, nephrologist, and P. Portegies, neurologist. This trial was internally funded at the Department of Neurology and Clinical Neurophysiology, Academic Medical Centre, University of Amsterdam.

\section{References}

I. Nelis E, Van Broeckhoven C, De Jonghe P, Lofgren A, Vandenberghe A, Latour P, Le Guern E, Brice A, Mostacciuolo ML, Schiavon F, Palau F, Bort S, Upadhyaya M, Rocchi M, Archidiacono N, Mandich P, Bellone E, Silander K, Savontaus ML, Navon R, Goldberg-Stern H, Estivill $X$, Volpini V, Friedl W, Gal A, et al:: Estimation of the mutation 
frequencies in Charcot-Marie-Tooth disease type I and hereditary neuropathy with liability to pressure palsies: a European collaborative study. Eur J Hum Genet 1996, 4:25-33.

2. Gabreëls-Festen AA, Joosten EM, Gabreëls FJ, Jennekens FG, Janssenvan Kempen TW: Early morphological features in dominantly inherited demyelinating motor and sensory neuropathy (HMSN type I). J Neurol Sci 1992, I07:| 45-154.

3. Robaglia-Schlupp A, Pizant J, Norreel JC, Passage E, Saberan-Djoneidi $D$, Ansaldi JL, Vinay L, Figarella-Branger D, Levy N, Clarac F, Cau P, Pellissier JF, Fontés M: PMP22 overexpression causes dysmyelination in mice. Brain 2002, I 25:2213-2221.

4. Garcia A, Combarros O, Calleja J, Berciano J: Charcot-MarieTooth disease type IA with I7p duplication in infancy and early childhood: a longitudinal clinical and electrophysiologic study. Neurology 1998, 50:106I-I067.

5. Killian JM, Tiwari PS, Jacobson S, Jackson RD, Lupski JR: Longitudinal studies of the duplication form of Charcot-Marie-Tooth polyneuropathy. Muscle Nerve 1996, 19:74-78.

6. Shy ME, Chen L, Swan ER, Taube R, Krajewski KM, Herrmann D, Lewis RA, McDermott MP: Neuropathy progression in CharcotMarie-Tooth disease type IA. Neurology 2008, 70:378-383.

7. Verhamme C, van Schaik IN, Koelman JH, De Haan RJ, de Visser M: The natural history of Charcot-Marie-Tooth type IA in adults: a 5-year follow-up study. Brain 2009 in press.

8. Berciano J, Garcia A, Calleja J, Combarros O: Clinico-electrophysiological correlation of extensor digitorum brevis muscle atrophy in children with Charcot-Marie-Tooth disease IA duplication. Neuromuscul Disord 2000, 10:419-424.

9. Verhamme C, van Schaik IN, Koelman JH, De Haan RJ, Vermeulen M, De Visser M: Clinical disease severity and axonal dysfunction in hereditary motor and sensory neuropathy la. J Neurol 2004, 25 I: |49|-|497.

10. Kaya F, Belin S, Bourgeois P, Micaleff J, Blin O, Fontes M: Ascorbic acid inhibits PMP22 expression by reducing cAMP levels. Neuromuscul Disord 2007, 17:248-253.

II. Passage E, Norreel JC, Noack-Fraissignes P, Sanguedolce V, Pizant J, Thirion X, Robaglia-Schlupp A, Pellissier JF, Fontes M: Ascorbic acid treatment corrects the phenotype of a mouse model of Charcot-Marie-Tooth disease. Nat Med 2004, 10:396-40I.

12. Food and Nutrition Board Institute of Medicine National Academy of Sciences: Dietary reference intakes for vitamin C, Vitamin E, Selenium, and Carotenoids. 2000 [http://www.nap.edu/cata log.php?record id=9810]. Washington DC: National Academy Press

13. van Dijk JG, Kamp WIM van der, van Hilten BJ, van Someren P: Influence of recording site on CMAP amplitude on its variation over a length of nerve. Muscle Nerve 1994, 17:1286-1292.

14. Tjon-A-Tsien AM, Lemkes HH, Kamp-Huyts AJ van der, van Dijk JG: Large electrodes improve nerve conduction repeatability in controls as well as in patients with diabetic neuropathy. Muscle Nerve 1996, 19:689-695.

15. Ploeg RJ van der, Fidler V, Oosterhuis HJ: Hand-held myometry: reference values. J Neurol Neurosurg Psychiatry 1991, 54:244-247.

16. Solari A, Laura M, Salsano E, Radice D, Pareyson D: Reliability of clinical outcome measures in Charcot-Marie-Tooth disease. Neuromuscul Disord 2008, 18:19-26.

17. Merkies IS, Schmitz PI, Meché FG van der, van Doorn PA: Psychometric evaluation of a new sensory scale in immune-mediated polyneuropathies. Inflammatory Neuropathy Cause and Treatment (INCAT) Group. Neurology 2000, 54:943-949.

18. Shy ME, Blake J, Krajewski K, Fuerst DR, Laura M, Hahn AF, Li J, Lewis RA, Reilly M: Reliability and validity of the CMT neuropathy score as a measure of disability. Neurology 2005, 64:1209-12 I4.

19. Weisscher N, Post B, De Haan RJ, Glas CAW, Speelman JD, Vermeulen M: The AMC Linear Disability Score in patients with newly diagnosed Parkinson disease. Neurology 2007, 69:2155-2161.

20. Merkies IS, Schmitz PI, Meche FG van der, Samijn IP, van Doorn PA: Clinimetric evaluation of a new overall disability scale in immune mediated polyneuropathies. I Neurol Neurosurg Psychiatry 2002, 72:596-601.

21. Mathiowetz V, Weber K, Kashman N, Volland G: Adult norms for the nine hole peg test of finger dexterity. Occupational Therapy J Research 1985, 5:24-38 [http://psycnet.apa.org/?fa=main.doiLand ing\&uid=|986-05316-00|]
22. van Dijk JP, Blok JH, Lapatki BG, van Schaik IN, Zwarts MJ, Stegeman DF: Motor unit number estimation using high-density surface electromyography. Clinical Neurophysiology 2008, I $19: 33-42$.

23. Vickers AJ, Altman DG: Statistics Notes: Analysing controlled trials with baseline and follow up measurements. BMJ 200I, 323: II23-II24.

24. Metz J, Hundertmark U, Pevny I: Vitamin C allergy of the delayed type. Contact Dermatitis 1980, 6:172-174.

25. Burns J, Ouvrier RA, Yiu EM, Joseph PD, Kornberg AJ, Fahey MC, Ryan MM: Ascorbic acid for Charcot-Marie-Tooth disease type IA in children: a randomised, double-blind, placebocontrolled, safety and efficacy trial. Lancet Neurol 2009, 8:537-544.

26. Toth C: Poor tolerability of high dose ascorbic acid in a population of genetically confirmed adult Charcot-Marie-Tooth IA patients. Acta Neurol Scand 2009, I 20:134-8.

27. Huxley C, Passage E, Robertson AM, Youl B, Huston S, Manson A, Sabéran-Djoniedi D, Figarella-Branger D, Pellissier JF, Thomas PK, Fontés M: Correlation between varying levels of PMP22 expression and the degree of demyelination and reduction in nerve conduction velocity in transgenic mice. Hum Mol Genet 1998, 7:449-458.

28. Ginter E: Endogenous ascorbic acid synthesis and recommended dietary allowances for vitamin C. Am J Clin Nutr 198I, 34: $|448-| 45 \mid$.

29. Reilly MM, de JP, Pareyson D: 136th ENMC International Workshop: Charcot-Marie-Tooth disease type IA (CMTIA) 8-10 April 2005, Naarden, The Netherlands. Neuromuscul Disord 2006, 16:396-402.

\section{Pre-publication history}

The pre-publication history for this paper can be accessed here:

\section{http://www.biomedcentral.com/1741-7015/7/70/prepub}

Publish with Bio Med Central and every scientist can read your work free of charge

"BioMed Central will be the most significant development for disseminating the results of biomedical research in our lifetime. "

Sir Paul Nurse, Cancer Research UK

Your research papers will be:

- available free of charge to the entire biomedical community

- peer reviewed and published immediately upon acceptance

- cited in PubMed and archived on PubMed Central

- yours - you keep the copyright 